\title{
Development of Environmentally Friendly Water-Based Synthetic Metal-Cutting Fluid
}

\author{
Yuzan Yu, Yugao Guo (Corresponding author), Lei Wang \& Enqi Tang \\ College of Environment and Chemical Engineering \\ Tianjin Polytechnic University, Tianjin 300160, China \\ E-mail: york_guo@yahoo.com
}

\begin{abstract}
This paper introduces a method for preparation of environmentally friendly water-based synthetic metal-cutting fluid, which is formulated with the self-made triethanolamine ricinoleate as base oil and other additives. This cutting fluid exhibits good cooling, cleaning, anti-rust, anti-corrosive and lubricating properties, is totally free of mineral oil, animal oil, nitrite that is harmful to the human body, phosphate that causes water pollution and etc., and has stable and reliable quality, long service life, easily available raw materials and low production cost. It is quite a perfect "environmentally friendly cutting fluid".
\end{abstract}

Keywords: Metal-cutting fluid, Triethanolamine ricinoleate, Water-based cutting fluid, Biodegradation, Base oil

\section{Preface}

Metal-cutting fluid, an indispensable additive in metal-cutting process, has functions of lubricating, cooling, cleaning, anti-rust and etc. It has remarkable effects on increasing the durability of cutter and the efficiency of production, improving the product quality, and prolonging the service life of cutter, in turn prolongs the service life of machine and ensures the stability and reliability of working conditions of machine. Therefore, research on cutting fluid technology, as well as improvement of cutting fluid quality play important roles in the modern mechanical processing industry. However, many commercially available cutting fluids contain organic sulfur, chlorine, nitrite and etc that are harmful to the human body and environment, which have severely negative effects on their applications (Feng, Jufen et al, 1995, p. 40-43).

The toxicity of cutting fluid causes harm to the human body. Under the conditions of high speed cutting or high load cutting, the resulted high temperature accelerates the oil-based cutting fluid to release harmful gases and oil mist, the lower the ignition point and viscosity of cutting fluid are, the severer the oil mist is. As for the water-based cutting fluid, the resulted micro-droplets irritate the mucous membrane of the respiratory system, and cause infection (Zeng, Qingliang et al, 2006, p. 113-115).

The environment pollutions resulted from cutting fluids mainly include two aspects as follows: (1) The erratic volatilization, spatter and leakage of cutting fluid during cutting process lead to a drastic environmental deterioration, and severely affect the safety of production; (2) mineral oil-based cutting fluid has a poor biodegradability, and will remain in water and soil for a long time, which causes contamination to lakes, rivers, oceans and underground water. Phosphate, a conventional anti-rust agent, is proved to be responsible for the red tides of lakes and rivers ( $\mathrm{Li}$, Chunfeng et al, 2001, p. 15-17).

Ester oil, a substitute for mineral oil, has a biodegradation rate of $90 \% \sim 100 \%$; however, it is rather expensive. Therefore, the further study on the fully biodegradable cutting fluid of moderate price has become more and more important throughout the world (Asadauskas, S et al, 1996, p. 877-882). Synthetic cutting fluid has advantages of being cheap, fast heat dissipation, being cleanable, excellent visibility in processing, being easy to dilute, high stability and perfect anti-rust ability. In addition, it is free of nutrients that support growth of microorganisms, and prevents the environment from being polluted (Kong Jixia, 2004, p. 49-52). However, the studies on the preparation conditions of base oil for synthetic cutting fluid have been rarely reported. This paper introduces a low-cost method for preparation of environmentally friendly triethanolamine ricinoleate, a base oil that substitutes for mineral oil, investigates the conditions for preparing this base oil, and formulates an environmentally friendly water-based synthetic metal-cutting fluid which is applicable for processing various metals. The above-mentioned base oil has an excellent solubility in 
water, and remarkably improves the lubricating ability, extreme pressure, anti-rust property and etc. of the cutting fluid.

\section{Experiment}

\subsection{Materials}

Castor acid (CP), from Tianjin Letai Chemical Industry Co., Ltd.; Soybean oil (food grade), from Tianjin Letai Chemical Industry Co., Ltd.; Castor oil (CP), triethanolamine (AR), concentrated sulfuric acid (AR), p-toluene sulphonic acid (AR), hydroquinone (AR), ferrous ammonium sulfate (AR), OP-10 (AR), dimethyl silicone oil (AR), sodium benzoate (AR), sodium gluconate (AR), benzotriazole (AR), and EDTA (AR), all from Tianjin Kermel Chemical Reagent Co., Ltd.

\subsection{Preparation of base oil}

A reddish brown triethanolamine ricinoleate of excellent water solubility is formulated at $90{ }^{\circ} \mathrm{C}$ for 150 min with castor acid and triethanolamine at the molar ratio of 1 to 3 , p-toluene sulphonic acid as the catalyst, as well as ferrous ammonium sulfate as the polymerization inhibitor. The reaction is expressed by the following equation (1).

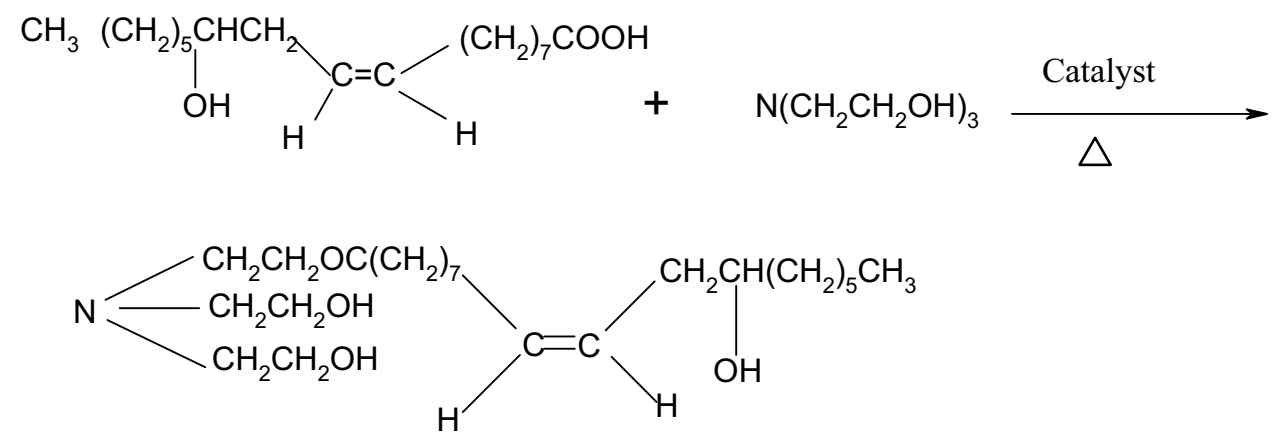

\subsection{Formulation design of cutting fluid}

The best designed formulation of cutting fluid has been obtained based on the orthogonal experiment of base oil, extreme pressure agent and other additives.

\subsection{Measurement of performances of cutting fluid}

Measure the performances of the obtained water-based synthetic metal-cutting fluid according to the national standard (GB6144-1985).

\section{Results and discussions}

\subsection{Determination of the best reactants for base oil}

Biodegradability of the base oil has a direct effect on that of the obtained cutting fluid. Therefore, the selection of base oil remarkably affects the effects of cutting fluid on the environment. The base oil of cutting fluid includes mineral oil, synthetic oil (synthetic ester and synthetic alkane) and vegetable oil. Mineral oil and synthetic alkane are not proper to be used as the base oil of the environmentally friendly cutting fluid because they are poor at biodegradability, and remain in water and soil for a long time to cause environment pollution; whereas vegetable oil and synthetic ester have good biodegradability. Therefore, in this study, we use castor acid, castor oil and soybean oil to react with triethanolamine respectively, and select a reactant of the best esterification effect to prepare the base oil. The results are shown in table 1.

From table 1, we can see that the product from triethanolamine and castor acid is much better than the other two groups as to the solubility and transparency, as a result, we select triethanolamine and castor acid as the best reactants for preparing the base oil.

\subsection{Determination of molar ratio of reactants}

Molar ratio of castor acid to triethanolamine has a direct effect on the reaction. Overhigh amount of castor oil leads to incomplete reaction, and has an adverse effect on the esterification; whereas overlow amount of castor oil leads to the waste of triethanolamime. Therefore, a proper molar ratio should be determined. By comparing the transparency, solubility and stability of the product, the paper investigates the effects of different molar ratio of castor acid to triethanolamine on the esterification under the same reaction conditions. Figure 1 exhibits the effects of molar ratio of castor acid to triethanolamine on the transparency of the obtained synthetic ester, and table 2 exhibits the effects of molar ratio of castor acid to triethanolamine on the solubility and stability of the obtained synthetic ester.

From figure 1 and table 2, we can see that the synthetic ester is good at the transparency, solubility and stability when the molar ratio of castor acid to triethanolamine is less than 1:3. In view of the production cost, the molar ratio of castor 
acid to triethanolamine is determined to be 1:3.

\subsection{Determination of the optimal reaction temperature}

Reaction temperature has a certain effect on the performances of the product. Overheat leads to the deterioration of castor acid, whereas overlow temperature results in incomplete reaction. Table 3 exhibits the effect of temperature on the performances of the obtained product.

From table 3, we can see that the reaction is slow and incomplete, and the product is viscous and insoluble when the reaction temperature is lower than $80{ }^{\circ} \mathrm{C}$; whereas the color of the product is darker and the transparency of the product is lower when the reaction temperature is higher than $130{ }^{\circ} \mathrm{C}$. Therefore, the reaction temperature should be in the range of $90 \sim 120{ }^{\circ} \mathrm{C}$.

\subsection{Determination of the optimal reaction period}

Reaction period also has a certain effect on the performances of the product. Overshort reaction period leads to incomplete reaction; whereas, overlong reaction results in more byproducts. Table 4 investigates the effects of reaction period on the stability of the ester at reaction temperature of $90 \sim 120{ }^{\circ} \mathrm{C}$.

From table 4, we can see that the stability of the synthetic ester increases with the reaction going on at low reaction temperature $\left(90 \sim 100{ }^{\circ} \mathrm{C}\right)$; whereas, the stability decreases and large amount of byproducts appear when the reaction temperature is over $110{ }^{\circ} \mathrm{C}$. In view of the production cost, it is determined to carry out the reaction at $90{ }^{\circ} \mathrm{C}$ for 150 $\min$.

\subsection{Selection of catalyst}

For further increase of reaction speed and production efficiency, we investigate the effect of different catalysts on the esterification at the optimal molar ratio, reaction period and reaction temperature (see table 5).

From table 5, we can see that the catalysis effect of p-toluene sulphonic acid is better than that of concentrated sulfuric acid. In addition, concentrated sulfuric acid leads to the increase of byproducts with the reaction going on at high temperature. Therefore, p-toluene sulphonic acid is selected as the catalyst in this study, and its amount is determined to be $0.5 \%$.

\subsection{Selection of polymerization inhibitor}

Besides the esterification, intermolecular polymerization and intramolecular polymerization also occur. Polymerization inhibitor is used to prevent molecular polymerization. Table 6 reveals the comparison between two polymerization inhibitors.

From table 6, we can see that these two inhibitors have the same effects. However, the water solution of hydroquinone appears reddish when oxidized in air, and affects the visibility of cutting fluid, meanwhile, it sort of has toxicity. Therefore, we select ferrous ammonium sulfate as the polymerization inhibitor in this study.

\subsection{Optimal formulation of cutting fluid}

Table 7 exhibits the optimal formulation of cutting fluid.

\subsection{Measurement of the product quality}

Measure the performances of the obtained water-based synthetic metal-cutting fluid according to the national standard (GB6144-1985). Table 8 exhibits the measurement results.

\subsection{Comparison with traditional cutting fluid}

Generally, traditional cutting fluids contain organic sulfur, chlorine, nitrite and etc that are harmful to the human body and environment, which have severely negative effects on their applications. In addition, mineral oil or synthetic alkane based cutting fluids have poor biodegradability, which further limits the application of traditional cutting fluid. However, synthetic ester-based cutting fluids have advantages of good biodegradability, being cheap, fast heat dissipation, being cleanable, excellent visibility in processing, being easy to dilute, high stability and perfect anti-rust ability, therefore they have bright future in the market. The only fly in the ointment is that the poor lubricating ability of synthetic ester-based cutting fluids limits their broader applications. In this study, the base oil, triethanolamine ricinoleate, is a nonionic surfactant. As a result, it can lower the friction, and increase the lubricating ability of cutting fluid. In addition, sodium gluconate exhibits an excellent synergistic effect with sodium benzoate, even small amount of sodium gluconate can remarkably increase the anti-rust effect of sodium benzoate.

\section{Conclusion}

A base oil of excellent water solubility, triethanolamine ricinoleate, is formulated at $90{ }^{\circ} \mathrm{C}$ for $150 \mathrm{~min}$ with castor acid and triethanolamine at the molar ratio of 1 to 3, p-toluene sulphonic acid as the catalyst, and ferrous ammonium sulfate as the polymerization inhibitor. An environmentally friendly water-based synthetic metal-cutting fluid is in turn 
formulated with this self-made base oil and other additives. The performances of this cutting fluid meet the requirements specified in the national standard GB 6144-1985. The test results indicate that this cutting fluid has good cooling, cleaning, anti-rust, anti-corrosive and lubricating properties, is totally free of mineral oil, animal oil, nitrite that is harmful to the human body, phosphate that causes water pollution and etc., and has stable and reliable quality, long service life, easily available raw materials and low production cost.

\section{References}

Asadauskas, S, Perez, J M \& Duda, J L. (1996). Oxidative stability and antiwear properties of high oleic vegetable oils. Lubrication Engineering, 52, 877-882.

Feng, Jufen, Sun, Daoyan \& Liao, Rongsu. (1995). A research on water-soluble cutting fluid. Journal of Beijing Forestry University, 17(3), 40-43.

Hou, Bin, Chen, Boshui \& Fang Jianhua. (2002). Some ideas about environmentally friendly metal cutting fluids. Lubrication Engineering, 4, 37-39.

Kong, Jixia. (2004). Present situation and development of synthetic cutting fluid. Gaoqiao Petrochemical Corporation, 19, 49-52.

Li, Chunfeng, Luo Xinmin \& Liu Ximei. (2001). Preliminary research of environmental protection cutting fluid. Synthetic Lubricants, 28(4), 15-17.

Zeng, Qingliang \& Xu Yan. (2006). Study on application of environmentally friendly cutting fluid. Machine Tool \& Hydraulics, 7, 113-115.

Table 1. The selection of base oil

\begin{tabular}{|c|c|c|c|c|c|c|c|c|c|}
\hline Reactant & \multicolumn{2}{|c|}{ Triethanolamine + castor acid } & \multicolumn{2}{c|}{ Triethanolamine + castor oil } & \multicolumn{2}{c|}{ Triethanolamine + soybean oil } \\
\hline Reaction temperature $\left({ }^{\circ} \mathrm{C}\right)$ & 120 & 140 & 160 & 120 & 140 & 160 & 120 & 140 & 160 \\
\hline Solubility* & ++ & + & +- & -- & -- & -- & -- & -- & +- \\
\hline Transparency** & $100 \%$ & $50 \%$ & $20 \%$ & - & - & - & - & - & - \\
\hline
\end{tabular}

* Solubility is classified into 5 grades, and expressed as,,,++++-- and - in order from fully soluble to insoluble.

** In $2 \%$ water solution, transparency is expressed with a percentage from $100 \%$ to $1 \%$ in order from transparent to milky, and 0 represents the transparency when the synthetic ester is insoluble.

Table 2. The effects of molar ratio on the solubility and stability of the obtained synthetic ester

\begin{tabular}{|c|c|c|c|c|c|c|c|c|c|}
\hline Molar ratio of castor acid to triethanolamine & $1: 1$ & $1: 1.2$ & $1: 1.4$ & $1: 1.6$ & $1: 1.8$ & $1: 2$ & $1: 2.5$ & $1: 3$ & $1: 4$ \\
\hline Solubility & -- & -- & - & +- & + & + & ++ & ++ & ++ \\
\hline Stability & 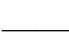 & - & $\longrightarrow$ & $30 \mathrm{~min}$ & $1 \mathrm{~h}$ & $2 \mathrm{~h}$ & $4 \mathrm{~h}$ & $\mathrm{~F}+$ & $\mathrm{F}+$ \\
\hline
\end{tabular}

$\mathrm{F}+$ represents that the obtained synthetic ester stays stable for a long time.

Table 3. The effects of reaction temperature on the performances of the obtained synthetic ester

\begin{tabular}{|c|c|c|c|c|c|c|c|}
\hline Reaction temperature $\left({ }^{\circ} \mathrm{C}\right)$ & 80 & 90 & 100 & 110 & 120 & 130 & 140 \\
\hline Solubility & + & ++ & ++ & ++ & ++ & + & + \\
\hline Transparency & $100 \%$ & $100 \%$ & $100 \%$ & $100 \%$ & $100 \%$ & $80 \%$ & $50 \%$ \\
\hline
\end{tabular}


Table 4 . The effects of reaction period on the stability of the obtained synthetic ester at different reaction temperature

\begin{tabular}{|c|c|c|c|c|c|c|c|c|}
\hline \multirow{2}{*}{ Reaction temperature $\left({ }^{\circ} \mathrm{C}\right)$} & \multicolumn{9}{|c|}{ Reaction period (min) } \\
\cline { 2 - 9 } & 30 & 60 & 90 & 120 & 150 & 180 & 210 & 240 \\
\hline 90 & $2 \mathrm{~d}$ & $2 \mathrm{~d}$ & $3 \mathrm{~d}$ & $4 \mathrm{~d}$ & $\mathrm{~F}+$ & $\mathrm{F}+$ & $\mathrm{F}+$ & $\mathrm{F}+$ \\
\hline 100 & $2 \mathrm{~d}$ & $2 \mathrm{~d}$ & $3 \mathrm{~d}$ & $4 \mathrm{~d}$ & $\mathrm{~F}+$ & $\mathrm{F}+$ & $\mathrm{F}+$ & $\mathrm{F}+$ \\
\hline 110 & $2 \mathrm{~d}$ & $2 \mathrm{~d}$ & $2 \mathrm{~d}$ & $2 \mathrm{~d}$ & $1 \mathrm{~d}$ & $1 \mathrm{~d}$ & $1 \mathrm{~d}$ & $1 \mathrm{~d}$ \\
\hline 120 & $30 \mathrm{~min}$ & $50 \mathrm{~min}$ & $60 \mathrm{~min}$ & $60 \mathrm{~min}$ & $60 \mathrm{~min}$ & $60 \mathrm{~min}$ & $60 \mathrm{~min}$ & $60 \mathrm{~min}$ \\
\hline
\end{tabular}

$\mathrm{F}+$ represents that the obtained synthetic ester stays stable for a long time.

Table 5. The effects of different catalysts on the performances of the obtained synthetic ester

\begin{tabular}{|c|c|c|c|c|}
\hline Catalyst & $\begin{array}{c}\text { p-toluene sulphonic } \\
\text { acid }(0.5 \%)\end{array}$ & $\begin{array}{c}\text { p-toluene sulphonic } \\
\text { acid }(1.0 \%)\end{array}$ & $\begin{array}{c}\text { Concentrated sulfuric } \\
\text { acid }(0.5 \%)\end{array}$ & $\begin{array}{c}\text { Concentrated sulfuric } \\
\text { acid }(1.0 \%)\end{array}$ \\
\hline Solubility & ++ & ++ & +- & -- \\
\hline Transparency & $100 \%$ & $100 \%$ & $30 \%$ & 0 \\
\hline
\end{tabular}

Table 6. The comparison between two polymerization inhibitors

\begin{tabular}{|c|c|c|c|}
\hline Polymerization inhibitors & Solubility & Transparency & Stability \\
\hline Hydroquinone & ++ & $80 \%$ & F+ \\
\hline Ferrous ammonium sulfate & ++ & $100 \%$ & F+ \\
\hline
\end{tabular}

Table 7. The formulation of cutting fluid

\begin{tabular}{|c|c|}
\hline Triethanolamine ricinoleate & $20 \%$ \\
\hline OP-10 & $1 \%$ \\
\hline Extreme pressure agent & $15 \%$ \\
\hline Dimethyl silicone oil & $1 \%$ \\
\hline Sodium benzoate & $0.5 \%$ \\
\hline Sodium gluconate & $0.5 \%$ \\
\hline Benzotriazole & $1 \%$ \\
\hline EDTA & A little \\
\hline Deionized water & Margin \\
\hline
\end{tabular}


Table 8 . The measurement of performances of the obtained cutting fluid

\begin{tabular}{|c|c|c|c|c|}
\hline \multicolumn{2}{|c|}{ Measured performances } & \multicolumn{2}{|c|}{ Quality index } & Test method \\
\hline \multirow{2}{*}{$\begin{array}{l}\text { Concentrated } \\
\text { fluid }\end{array}$} & Appearance & \multicolumn{2}{|c|}{ Transparent solution } & GB6144-85 \\
\hline & Storage stability & \multicolumn{2}{|c|}{ Qualified } & GB6144-85 \\
\hline \multirow{11}{*}{$\begin{array}{l}5 \% \text { solution of } \\
\text { ionized water }\end{array}$} & Transparency & \multicolumn{2}{|c|}{ Transparent } & GB6144-85 \\
\hline & $\mathrm{pH}$ & \multicolumn{2}{|c|}{$8 \sim 9$} & GB6144-85 \\
\hline & Defoaming property & \multicolumn{2}{|c|}{ Qualified } & GB6144-85 \\
\hline & Surface tension & $0.031 \mathrm{dy}$ & & GB6144-85 \\
\hline & \multirow{3}{*}{ Anti-corrosion $\left(55 \pm 2{ }^{\circ} \mathrm{C}\right)$} & Grey cast iron & Grade A & GB6144-85 \\
\hline & & Red copper & Grade A & GB6144-85 \\
\hline & & LY12 Aluminum & Grade A & GB6144-85 \\
\hline & \multirow{2}{*}{ Anti-rust } & Single layer & Grade A & GB6144-85 \\
\hline & & Laminated layer & Grade A & GB6144-85 \\
\hline & Maximum non-seizure load (PB) & \multicolumn{2}{|c|}{$\leq 150 \mathrm{~kg}$} & GB6144-85 \\
\hline & Compatibility with the machine paint & \multicolumn{2}{|c|}{ Qualified } & GB6144-85 \\
\hline
\end{tabular}

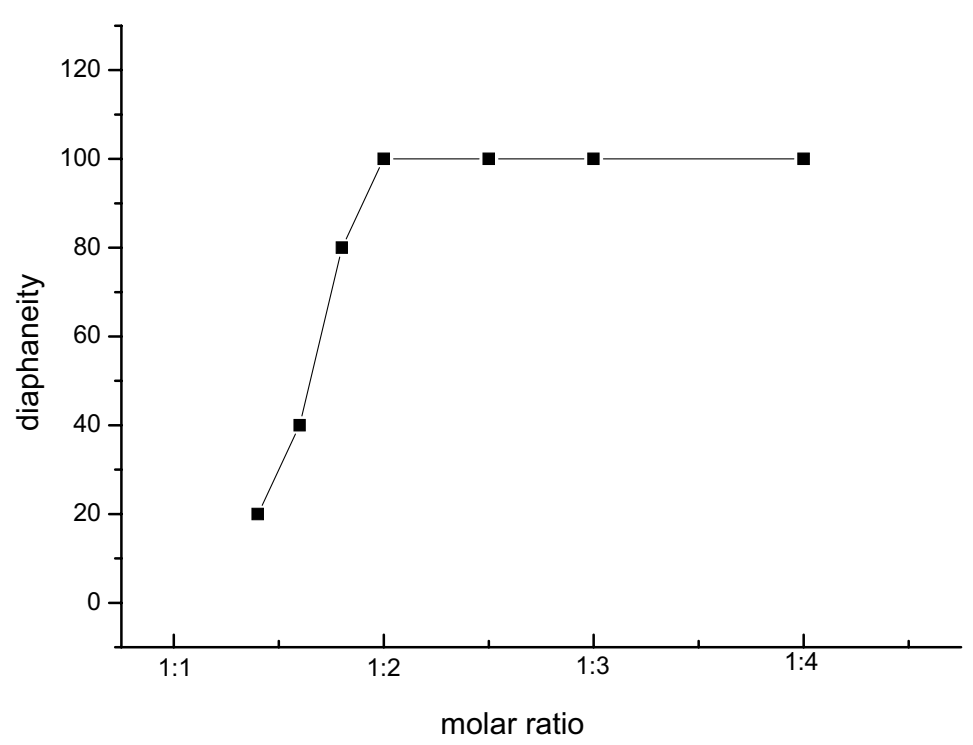

Figure 1. The effect of molar ratio of castor acid to triethanolamine on the transparency of the obtained synthetic ester 